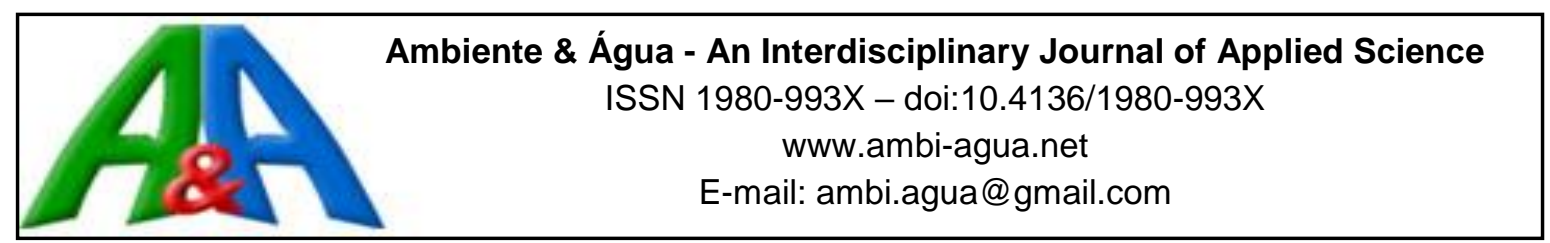

\title{
Comparação entre metodologias de amostragem de água para quantificação de variáveis limnológicas em ambiente lótico
}

\author{
doi:10.4136/ambi-agua.1781
}

Received: 08 Oct. 2015; Accepted: 06 Dec. 2016

\author{
Mayana Silva Bessa Leite; Flávia Mariani Barros*; \\ Danilo Paulúcio da Silva; Romário Oliveira de Santana; \\ Jhones da Silva Amorim; Stênio Rocha de Carvalho
Universidade Estadual do Sudoeste da Bahia (UESB), Itapetinga, BA, Brasil
Departamento de Ciências Exatas e Naturais
*Autor correspondente: e-mail: mariamariani@yahoo.com.br, mayanabessa@hotmail.com,dpaulucio@uesb.edu.br, romarioliver1@hotmail.com,jhones_sa@hotmail.com, steniophn@hotmail.com

\section{RESUMO}

Objetivou-se, com o presente trabalho, avaliar duas metodologias de amostragem de água (amostra coletada na profundidade de $15-30 \mathrm{~cm}$ e amostra integrada), para determinação de variáveis limnológicas em uma seção transversal do rio Catolé Grande, em diferentes níveis de vazão. Foram quantificadas as variáveis turbidez, $\mathrm{pH}$, condutividade elétrica, oxigênio dissolvido e coliformes totais. A comparação dos resultados obtidos, segundo as diferentes metodologias de coleta utilizadas foi realizada utilizando os índices estatísticos eficiência do modelo e coeficiente de determinação e por meio de análise de regressão linear. Houve pequena influência das metodologias de amostragem em relação às variáveis turbidez, condutividade e coliformes totais. Para a variável $\mathrm{pH}$, a amostragem realizada de $15-30 \mathrm{~cm}$ de profundidade ocasionou superestimativa dos valores quando comparados à amostra integrada. Com relação à variável oxigênio dissolvido, os valores obtidos a partir da amostragem de $15-30 \mathrm{~cm}$ tedem a superestimativas quando as concentrações são inferiores a $6,5 \mathrm{mg} \mathrm{L} \mathrm{L}^{-1}$, entretanto, quando a concentação é superior a esse valor, esse tipo de amostragem tende a subestimar quando comparada aos valores obtidos por meio da amostra integrada.

Palavras-chave: qualidade da água, pontos de amostragem, vazão.

\section{Comparison of different water sampling methods to quantify limnological variables in a lotic environment}

\begin{abstract}
This study evaluated water sampling methodologies for determining limnological variables in a cross section of the Catole Grande River at different flow rates. Samples were collected at depths of $15-30 \mathrm{~cm}$ and compared with integrated samples. The variables of turbidity, $\mathrm{pH}$, electrical conductivity, dissolved oxygen and total coliforms were quantified. The results were compared, according to the different collection methodologies, using the statistical index, model efficiency, coefficient of determination, and linear regression analysis. There was little influence of the sampling methodologies in relation to turbidity, conductivity
\end{abstract}


and total coliforms variables. For the $\mathrm{pH}$ variable, the sampling performed at $15-30 \mathrm{~cm}$ depth caused overestimation when compared to the integrated sample. Regarding the dissolved oxygen variable, the values obtained using $15-30 \mathrm{~cm}$ samples tend to overestimate when the concentrations are lower than $6.5 \mathrm{mg} \mathrm{L}^{-1}$; however, when the concentration is higher than this value, this type of sampling tends to underestimated when compared to values obtained using the integrated samples.

Keywords: flow rate, sampling points, water quality.

\section{INTRODUÇÃO}

Para programas de amostragem é importante considerar que a qualidade da água superficial pode variar conforme o local e o tempo. Na seleção do ponto para coleta das amostras em cursos d'água, dois aspectos estão envolvidos: a definição da seção transversal e a cota na posição a ser monitorada (Hynes, 1970).

A Companhia Ambiental do Estado de São Paulo (CETESB, 1988) sugere que coletas de água sejam feitas na calha central do rio na profundidade de 15 a $30 \mathrm{~cm}$. No entanto, a coleta realizada desta forma pode não suprir a necessidade de estudo para alguns casos específicos, sendo necessário estudo mais detalhado das variáveis de qualidade da água ao longo da seção transversal de um rio. Isto pode ser confirmado em estudo realizado por Barros et al. (2012) no Rio Turvo Sujo - MG, no qual os autores recomendaram, nas condições por eles avaliadas, que a amostragem seja feita a $20 \mathrm{~cm}$ de profundidade em relação à superfície e considerando-se a amostra integrada composta por amostras coletadas em três pontos na seção transversal do curso d'água (esquerdo, central e direito) para as variáveis condutividade elétrica, fósforo total dissolvido, fósforo inorgânico dissolvido, amônio e nitrato. Para as variáveis oxigênio dissolvido, turbidez, $\mathrm{pH}$, fósforo total, fósforo inorgânico dissolvido e nitrogênio total, recomenda-se amostragem integrada composta por amostras de água coletadas em três pontos (superfície, meio e fundo), na coluna central do curso d'água (Barros et al., 2012).

Partindo-se desse pressuposto e considerando a escassez estudos que visem comparar metodologias de amostragem em ambientes lóticos que não sofrem influência de contaminação por fontes pontuais de poluição, o objetivo do presente estudo foi comparar duas metodologias utilizadas para amostragem de água em seção transversal de um ambiente lótico.

\section{MATERIAL E MÉTODOS}

A seção transversal monitorada considerada neste estudo está situada no rio Catolé Grande, com coordenadas geográficas $15^{\circ} 14^{\prime} 6,3^{\prime \prime}$ s e $40^{\circ} 16^{\prime} 30,7 " \mathrm{w}$, sendo este pertencente à bacia hidrográfica do rio Pardo no Estado da Bahia. A bacia hidrografica do rio Catolé Grande está contida entre os paralelos 8379377 e 8300757 m e entre os meridianos 299725 e 379475 m em coordenadas UTM (zona 24).

No local onde foram realizadas as coletas das amostras de água do rio Catolé Grande, a largura média da seção transveral em estudo variou entre 14,2 e $15 \mathrm{~m}$ e a profundidade média entre 0,57 e 1,03 m. Foram realizadas seis coletas em diferentes épocas do ano de 2013, nas quais as vazões do rio variaram de $4,33 \mathrm{~m}^{3} \mathrm{~s}^{-1}$ a $11,25 \mathrm{~m}^{3} \mathrm{~s}^{-1}$; esta faixa de vazão apresenta uma permanência de $43 \%$ na série histórica da bacia (série histórica de 56 anos, estação: 53780000).

As metodologias de coleta de águas superficiais avaliadas no presente estudo foram: metodologia proposta na NBR 9897/87, em que se recomenda a obtenção de uma amostra 
integrada por amostras simples coletadas em diferentes pontos da seção avaliada (a depender da largura e profundidade da seção); metodologia proposta pela CETESB (1988) na qual se recomenda a coleta da amostra no centro da seção transversal de 15 a $30 \mathrm{~cm}$ de profundidade do curso d'água.

No primeiro método, para a escolha dos pontos de amostragem, a seção do curso d'água foi subdividida em três subseções de igual largura. As amostras foram coletadas no meio de cada subseção, à metade da profundidade.

Para a análise de cada metodologia, a quantificação das variáveis limnológicas foi realizada em triplicata. Em cada amostra de água coletada, foi quantificado o $\mathrm{pH}$, a turbidez (TUR), a condutividade elétrica (CE), o oxigênio dissolvido (OD) e a contagem de coliformes totais (CT), segundo metodologias descritas em Matos (2012), baseadas em APHA (2005).

A comparação das metodologias de amostragem foi realizada utilizando o coeficiente de determinação $\left(\mathrm{R}^{2}\right)$, o índice de eficiência do modelo (EF) e análise de regressão linear.

Para a medição da velocidade da água na seção transversal do rio Catolé Grande por ocasião de cada campanha de coleta de água utilizou-se molinete hidrométrico digital marca Global Water, modelo FP211. Os procedimentos para medição de vazão foram adotados de acordo com metodologia descrita em CETESB (2011).

\section{RESULTADOS E DISCUSSÃO}

Na Figura 1 é apresentada a comparação dos valores de turbidez (TUR) observados em amostras de água coletadas em uma seção transversal do rio Catolé Grande, para diferentes níveis de vazão, obtidos segundo duas metodologias de amostragem: CESTESB (1988) (Mc) e NBR 9897/87 (Mnbr). Também se encontram representados, na mesma figura, a linha de tendência ajustada a partir dos dados de turbidez obtidos considerando a metodologia $\mathrm{Mc}$ em função da Mnbr, os índices $\mathrm{R}^{2}$, EF e a reta identidade. A reta identidade representa um alinhamento em que os valores obtidos pelas duas metodologias de amostragem seriam iguais.

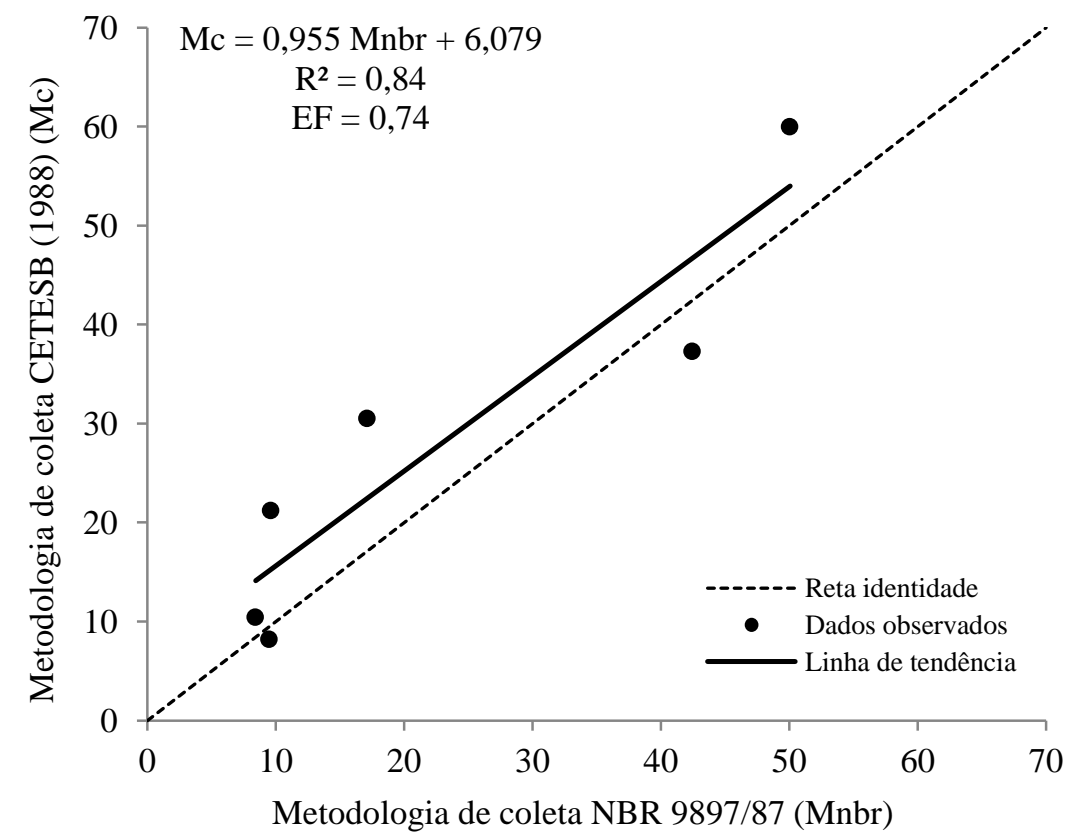

Figura 1. Valores de turbidez em UNT (TUR) em amostras de água coletadas considerando-se a metodologia de coleta da CETESB (1988) versus os obtidos em amostras coletadas seguindo-se a metodologia da NBR 9897/87, em diferentes vazões em uma seção transversal no rio Catolé Grande. 
De acordo com a Figura 1, observa-se semelhança entre metodologias de amostragem para esta variável, uma vez que o coeficiente de determinação $\left(\mathrm{R}^{2}\right)$ e o índice de eficiência das metodologias (EF) apresentaram valores altos, 0,84 e 0,74 respectivamente. Embora na maioria das campanhas de coleta, a amostragem realizada segundo a CETESB (1988) ter indicado valores maiores de turbidez em relação à amostragem realizada segundo a NBR 9897/87 (ABNT, 1987), nota-se na função que o coeficiente angular está próximo a 1 e o coeficiente linear, apesar de não ter sido zero, apresenta um valor baixo quando observa-se a escala de valores desta variável, indicando condição de semelhança entre as metodologias de amostragem.

As metodologias de amostragem provavelmente apresentaram condição de semelhança devido à presença de partículas finas em suspensão, como silte e argila. Esses tipos de particulas possuem distribuição homogênea ao longo da coluna liquída de dada seção de um curso d'água. Assim, independente da amostragem ter sido feito na metade ou a $30 \mathrm{~cm}$ de profundidade, a distribuição homogênea das particulas tende a conduzir valores de turbidez próximos.

Na Figura 2 é apresentada a comparação dos valores de potencial hidrogeniônico ( $\mathrm{pH}$ ) observados em uma seção transversal do rio Catolé Grande em diferentes níveis de vazão, obtidos segundo duas metodologias de amostragem: CESTESB (1988) (Mc) e NBR 9897/87 (Mnbr). Também se encontra representado, nesta figura, a linha de tendência, os índices $\mathrm{R}^{2} \mathrm{e}$ EF e a reta identidade.

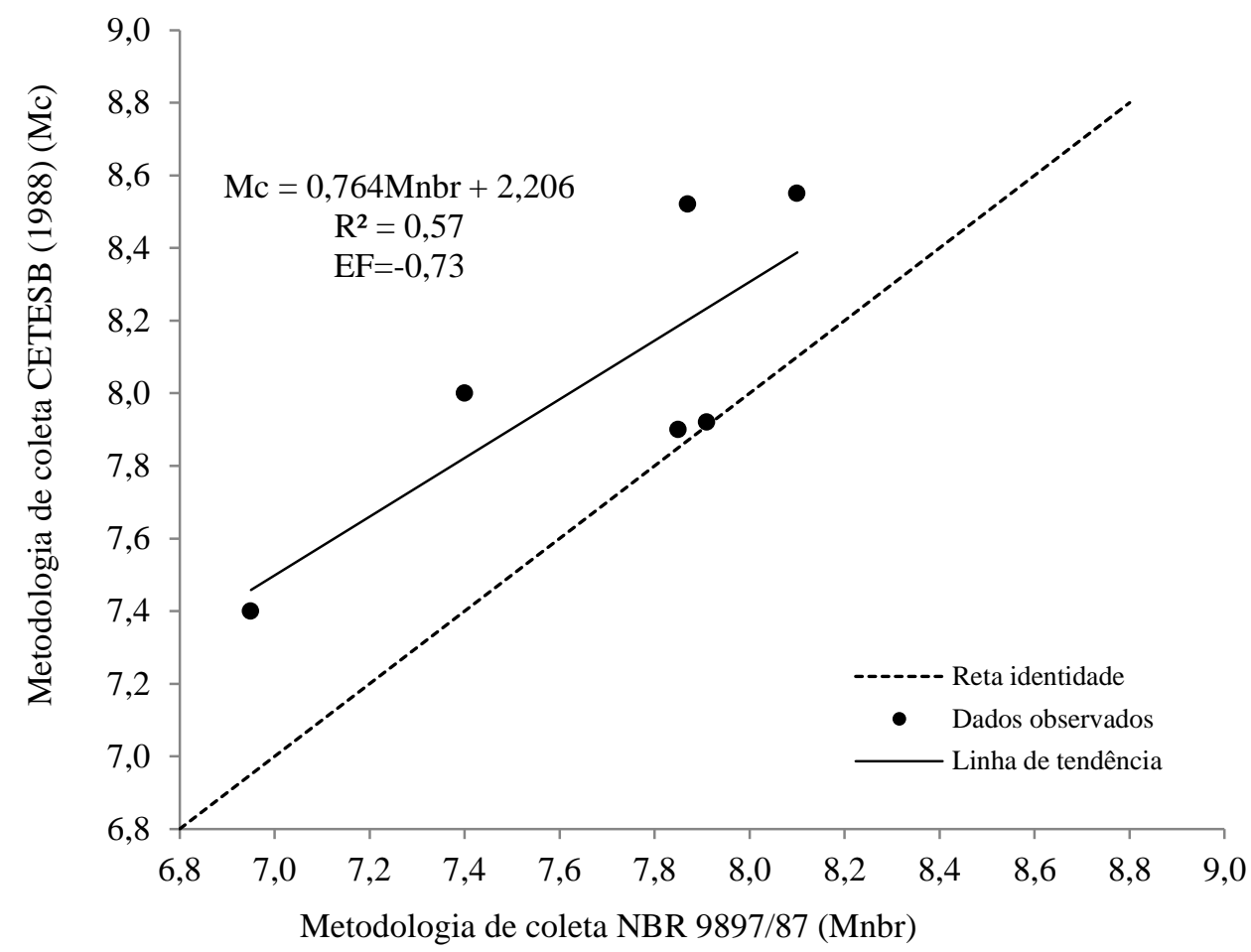

Figura 2. Valores de potencial hidrogeniônico $(\mathrm{pH})$ em amostras de água coletadas considerando-se a metodologia de coleta da CETESB (1988) versus os obtidos em amostras coletadas seguindo-se a metodologia da NBR 9897/87, em diferentes vazões em uma seção transversal no rio Catolé Grande. 
De acordo com a Figura 2, nota-se comportamento distinto entre o resultado obtido a partir das metodologias de amostragem para esta variável, onde o $\mathrm{R}^{2}$ e o EF apresentaram valores baixos, 0,57 e - 0,73, respectivamente. Além disso, é possível observar que a função apresenta um coeficiente angular que não é próximo a 1 e um coeficiente linear alto em relação a escala de valores desta variável, indicando que não há condição de semelhança entre as metodologias de amostragem adotadas.

Verifica-se que os valores na concentração do pH são influenciados pela metodologia de amostragem. Desta forma, foi observado que houve tendência da amostragem realizada segundo a metodologia da CETESB conduzir a maiores valores de $\mathrm{pH}$ quando comparados com os valores obtidos a partir de amostras coletadas segundo a proposição da NBR 9897/87. Nota-se ainda que a diferença dos valores de $\mathrm{pH}$ obtidos segundo as metodologias de amostragem tende a aumentar com redução do $\mathrm{pH}$.

Generoso et al. (2010) analisaram variáveis de qualidade de água neste mesmo rio, em diferentes épocas e pontos de uma seção transversal. Os autores observaram que o pH apresentou diferentes valores em relação aos distintos pontos de coleta e em relação às épocas avaliadas, corroborando com os resultados encontrados no presente trabalho.

Barros et al. (2012), com o objetivo de comparar a distribuição quantitativa de algumas variáveis de qualidade de água e verificar qual o local mais apropriado para coleta de água em uma seção transversal do Rio Turvo Sujo, Minas Gerais, observaram que houve diferença significativa entre as variáveis analisadas e os pontos de amostragem, assim como constatado no presente trabalho. Os autores recomendam para a variável $\mathrm{pH}$ a amostragem integrada constituída por amostras simples coletadas em três pontos (superfície, meio e fundo) na coluna central do curso d'água.

Na Figura 3 é apresentada a comparação dos valores de condutividade elétrica (CE) observados em uma seção transversal do rio Catolé Grande em diferentes níveis de vazão, obtidos segundo duas metodologias de amostragem: CESTESB (1988) (Mc) e NBR 9897/87 (Mnbr). De acordo com os dados apresentados na Figura 3 é possível observar condição de semelhança entre as metodologias de amostragem para esta variável, onde o $R^{2}$ e o EF apresentaram valores altos, 0,98 nos dois índices. Além disso, a função apresenta um coeficiente angular bem próximo a 1 e, embora tenha apresentado coeficiente linear diferente de zero, o valor encontrado de 2,170 é muito baixo, tendo em vista a escala de valores encontrados de CE.

A condição de semelhança entre as metodologias de amostragem ocorreu provavelmente devido à dispersão dos íons dissolvidos ser uniforme na seção transversal e no decorrer das verticais do curso d'água, não havendo aumento ou diminuição nos valores desta variável por nenhuma das metodologias de amostragem adotadas.

Em estudo realizado por Oliveira et al. (2008) em riachos da microbacia do rio São Francisco Verdadeiro - PR, com o objetivo de caracterizar espacial e temporalmente os riachos em função de fatores limnológicos, os autores verificaram que a condutividade elétrica não apresentou diferenças significativas espacialmente ao longo dos pontos de amostragem, o que também foi verificado no presente trabalho.

Barros et al. (2012), com o objetivo de comparar a distribuição quantitativa de algumas variáveis de qualidade de água e verificar o local mais apropriado para coleta de amostras de água em uma seção transversal do Rio Turvo Sujo, Minas Gerais, observaram que houve diferença significativa entre as variáveis analisadas e os pontos de amostragem. Os autores recomendaram que, para a variável condutividade elétrica, a amostragem seja realizada a $20 \mathrm{~cm}$ de profundidade em relação à superfície, com amostra integrada composta por amostras simples coletadas em três pontos (esquerdo, central e direito) do curso d'água. 


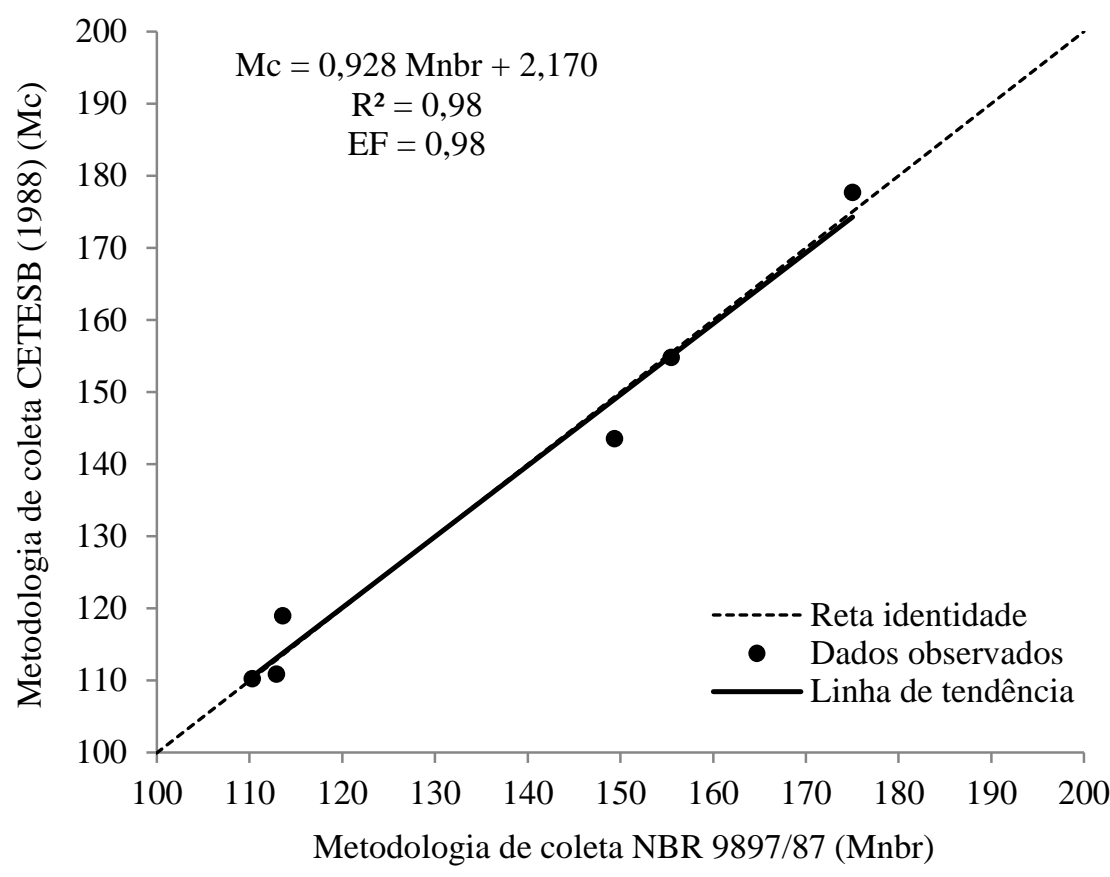

Figura 3. Valores de condutividade elétrica em $\mu \mathrm{S} \mathrm{cm}^{-1}$ (CE) em amostras de água coletadas considerando-se a metodologia de coleta da CETESB (1988) versus os obtidos em amostras coletadas seguindo-se a metodologia da NBR 9897/87, em diferentes vazões em uma seção transversal no rio Catolé Grande.

Na Figura 4 é apresentada a comparação dos valores de oxigênio dissolvido (OD) observados em uma seção transversal do rio Catolé Grande em diferentes níveis de vazão, obtidos segundo duas metodologias de coleta: CESTESB (1988) (Mc) e NBR 9897/87 (Mnbr). De acordo com os dados apresentados na Figura 4 nota-se que não houve grandes semelhanças entre as metodologias de amostragem para esta variável. Apesar do $\mathrm{R}^{2}$ e o EF, apresentarem valores moderados, 0,79 e 0,70 respectivamente, a função apresenta um coeficiente angular distante de 1 e um coeficiente linear muito alto para a escala de valores de OD obtidos, indicando que não há uma condição de semelhança entre as metodologias de amostragem.

$\mathrm{Na}$ amostragem realizada segundo a CETESB (1988) foi constatado que em duas das coletas houve o aumento nos valores de OD em relação a amostragem realizada segundo a NBR 9897/87. Segundo Barros et al. (2012) a taxa de reintrodução de oxigênio dissolvido em águas naturais por meio da superfície depende das características hidráulicas e é proporcional à velocidade, sendo que a taxa de reaeração superficial em uma cascata é maior do que a de um rio de velocidade normal, que por sua vez, apresenta taxa superior à de uma represa, onde a velocidade normalmente é bastante baixa. No presente trabalho a velocidade da água foi cerca de $50 \%$ maior no centro da seção $\left(0,6 \mathrm{~m} \mathrm{~s}^{-1}\right)$ em relação às margens $\left(0,47 \mathrm{~m} \mathrm{~s}^{-1}\right)$, assim como, na superfície em relação à profundidade da coluna d'água. Desta forma era esperado que realmente houvesse diferença entre as metodologias de amostragem.

Em estudo realizado por Rocha et al. (2010) neste mesmo rio, os autores verificaram que para a variável oxigênio dissolvido, os valores obtidos nas amostragens realizadas à profundidade de $0-20 \mathrm{~cm}$ foram sempre superiores aos valores referentes a amostragem realizada por integração vertical com o auxílio do amostrador de sedimentos. Os autores concluíram que essa situação pode ter sido ocasionada, devido ao fato de, na parte mais próxima ao fundo do rio, haver grande quantidade de sedimentos, os quais estão relacionados a maior demanda de oxigênio e, consequentemente, diminuição nos valores de oxigênio 
dissolvido. Este fato pode estar associado aos resultados encontrados no presente trabalho, onde houve o aumento nos valores desta variável na Mc em relação a Mnbr.

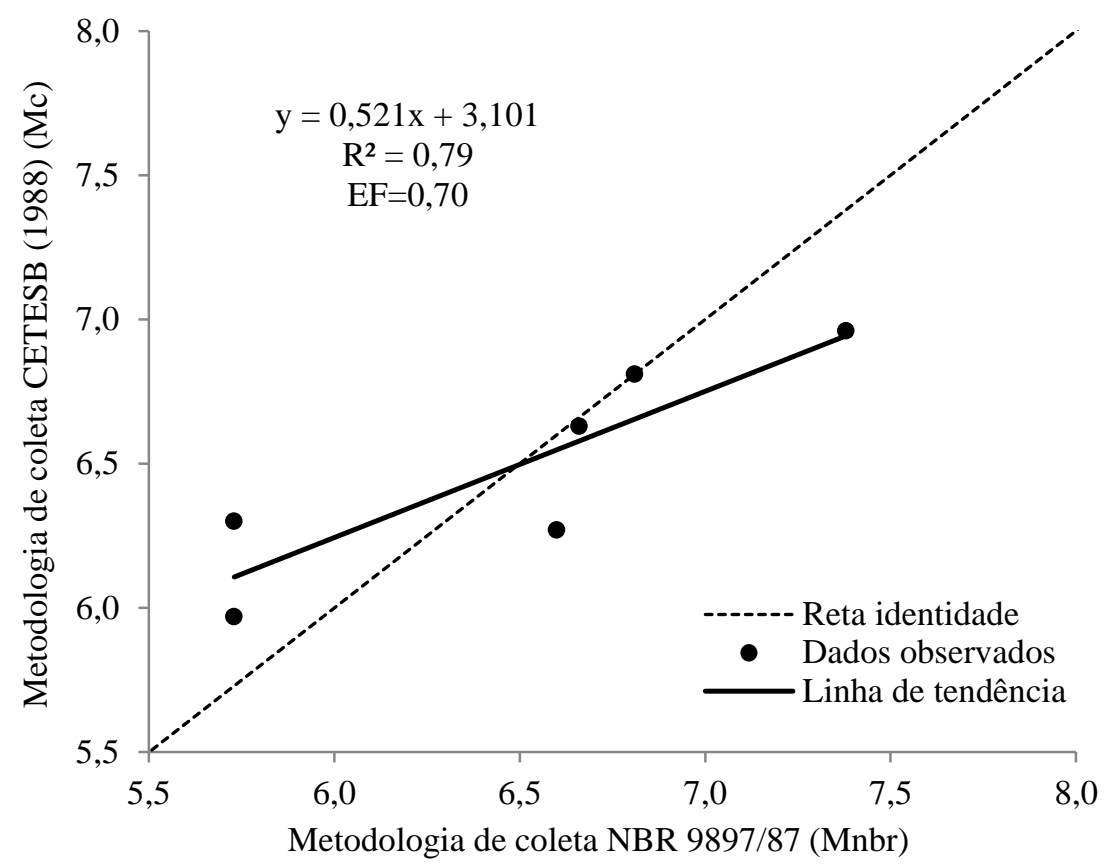

Figura 4. Valores de oxigênio dissolvido em $\mathrm{mg} \mathrm{L}^{-1}$ (OD) em amostras de água coletadas considerando-se a metodologia de coleta da CETESB (1988) versus os obtidos em amostras coletadas seguindo-se a metodologia da NBR 9897/87, em diferentes vazões em uma seção transversal no rio Catolé Grande.

Generoso et al. (2010), avaliando variáveis de qualidade de água no rio Catolé Grande, em diferentes épocas e pontos distintos de uma seção transversal, também encontraram grandes variações na concentração de oxigênio dissolvido em relação às observadas em amostras coletadas em outros pontos do curso d'água.

Na Figura 5 é apresentada a comparação dos valores de contagem de coliformes totais (CT) em amostras de água coletadas em uma seção transversal do rio Catolé Grande, em diferentes níveis de vazão, obtidos segundo as já referidas duas metodologias de coleta. Para essa mesma variavel foi observado condição de semelhança entre as metodologias de amostragem em relação a esta variável, visto que o $\mathrm{R}^{2}$ e o EF apresentaram valores altos, 0,90 nos dois índices (Figura 5). Além disso, a função apresenta coeficiente angular bem próximo a 1 e coeficiente linear com valor baixo em relação a escala de valores de CT.

Foram registrados valores mais próximos entre si para esta variável ao longo da seção transversal e verticais avaliadas no curso d'água, indicando que houve grandes semelhanças entre as metodologias de amostragem. Tal comportamento ocorreu, provavelmente, em viturde de que a maior parte das bactérias encontradas nos CT, sejam encontradas juntamente com os sedimentos finos em suspensão, os quais têm uma distribuição uniforme no decorrer do perfil.

De acordo com von Sperling (2007), as bactérias do grupo coliforme estão presentes no intestino humano e de animais de sangue quente, sendo eliminadas nas fezes em números elevados. Entretanto, o grupo dos coliformes inclui bactérias não exclusivamente de origem fecal, podendo ocorrer naturalmente no solo, água e plantas. Neste sentido, juntamente com os sedimentos seguem possíveis contaminantes, dentre eles as bactérias que compõem os CT provindos de fezes de animais. 
De modo geral, avaliando as metodologias de amostragem adotadas em relação as variáveis limnológicas analisadas, é possível observar que embora tenha ocorrido diferença entre as metodologias de amostragem, para algumas variáveis, esta não foi suficiente para modificar a condição de qualidade das águas do curso d'água (água doce classe 2), segundo a Resolução no 357 do CONAMA (2005), na seção transversal analisada no rio Catolé Grande. No entanto, para estudos voltados para caracterização limnológica das águas do curso d'água, nota-se que houve diferenças entre as metodologias de amostragem adotadas para a maior parte das variáveis.

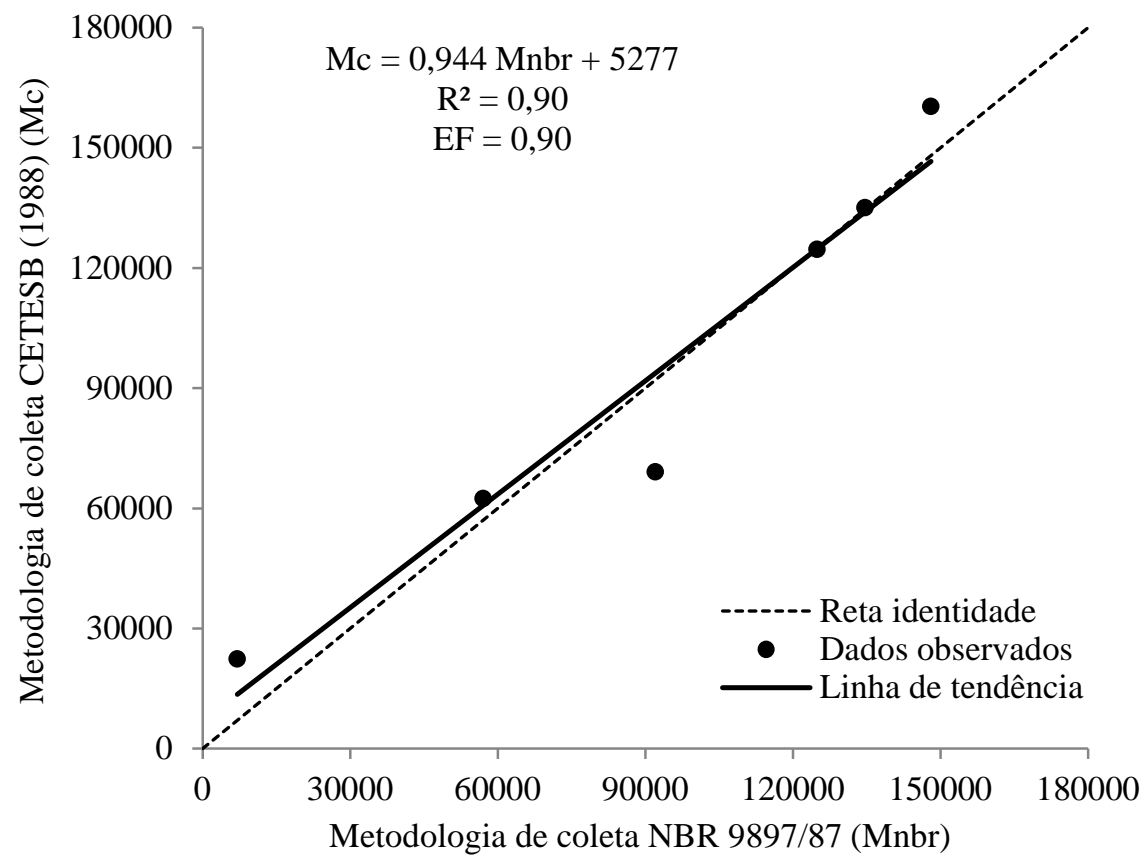

Figura 5. Valores de coliformes totais NMP $100 \mathrm{~mL}^{-1}$ (CT) em amostras de água coletadas considerando-se a metodologia de coleta da CETESB (1988) versus os obtidos em amostras coletadas seguindo-se a metodologia da NBR 9897/87, em diferentes vazões em uma seção transversal no rio Catolé Grande.

Vale salientar que estas metodologias de amostragem podem ser utilizadas para a determinação das variáveis limnológicas analisadas no presente estudo, em cursos d'água com características hidrológicas semelhantes as do rio Catolé Grande e em locais onde não há contaminação por fontes pontuais de poluição à montante.

\section{CONCLUSÃO}

Tendo por base os resultados obtidos, pode-se concluir que:

Houve pequena influência das metodologias de amostragem da CETESB (1988) e NBR 9897/87 em relação às variáveis limnológicas turbidez, condutividade elétrica e coliformes totais em amostras de água coletadas em uma seção transversal do rio Catolé Grande.

Para a variável pH a amostragem realizada segundo a CETESB (1988) ocasionou superestimativa dos valores quando comparados à amostra integrada enquanto que, em relação à variável oxigênio dissolvido os valores obtidos a partir deste tipo de amostragem apresentaram tendência de superestimativas quando as concentrações foram inferiores a $6,5 \mathrm{mg} \mathrm{L}^{-1}$, e subestimativas quando as concentrações foram superiores a esse valor. 
Em nenhum dos casos, a diferença entre os dois tipos de amostragem foi suficiente para modificar a condição de qualidade do curso d'água.

\section{AGRADECIMENTOS}

À Fundação de Amparo à Pesquisa do Estado da Bahia (FAPESB) e ao Conselho Nacional de Pesquisa e Desenvolvimento (CNPq) pelo apoio financeiro concedido para realização desta pesquisa (termo de outorga n. PPP0062/2011). À Universidade Estadual do Sudoeste da Bahia pelas bolsas concedidas.

\section{REFERÊNCIAS}

ASSOCIAÇÃO BRASILEIRA DE NORMAS TÉCNICAS. NBR 9897: planejamento de amostragem de efluentes líquidos e corpos receptores - procedimento. Rio de Janeiro, 1987. $14 \mathrm{p}$.

BARROS, F. M.; MARTINEZ M. A.; MATOS A. T. de; MOREIRA, D. A. Distribuição quantitativa de variáveis de qualidade da água coletada em diferentes pontos de um perfil transversal do rio turvo sujo - MG. Engenharia na agricultura, v. 20, n. 1, p. 60 69, 2012.

COMPANHIA DE TECNOLOGIA DE SANEAMENTO AMBIENTAL DO ESTADO DE SÃO PAULO - CETESB. Guia de coleta e preservação de amostras de água. São Paulo, 1988. $160 \mathrm{p}$.

COMPANHIA DE TECNOLOGIA DE SANEAMENTO AMBIENTAL DO ESTADO DE SÃO PAULO- CETESB. Guia nacional de coleta e preservação de amostras: água, sedimento, comunidades aquáticas e efluentes líquidos. São Paulo: CETESB; Brasília: ANA, 2011. 325 p.

CONSELHO NACIONAL DO MEIO AMBIENTE (Brasil) - CONAMA. Resolução n. ${ }^{\circ}$ 357, de 17 de Março de 2005. Dispõe sobre a classificação dos corpos de água e diretrizes ambientais para o seu enquadramento, bem como estabelece as condições e padrões de lançamento de efluentes, e dá outras providências. Diário Oficial [da] União, Brasília, DF, n. 53, 18 mar. 2005.

GENEROSO, T. N.; FRAGA, D. S.; TAGLIAFERRI, C.; ROSA, R. C. C. Influência do local de amostragem nos valores de variáveis de qualidade de água em uma seção transversal do rio Catolé - BA, Enciclopédia Biosfera, v. 6, n. 11, 2010.

HYNES, H. B. N. The ecology of running waters. 3. ed. Liverpool: University Press, 1970. $555 \mathrm{p}$.

MATOS, A. T. de. Qualidade do meio físico e ambiental. 1.ed. Viçosa: Ed. UFV, 2012. 150 p.

OLIVEIRA, L. C.; GOMES, B. M.; BAUMGARTNER, G.; SEBASTIEN, N. Y. Variação espacial e temporal dos fatores limnológicos em riachos da microbacia do rio são francisco verdadeiro - PR. Engenharia Agrícola, v. 28, n. 4, p. 770-781, 2008. http://dx.doi.org/10.1590/S0100-69162008000400017

ROCHA, F. A.; SATURNINO, M. C. O. MELO, A. R. B.; BARROS, F. M.; BARRETO, L. V. Variáveis de qualidade de água influenciadas pelo tipo e época de amostragem, no rio Catolé - BA. Enciclopédia Biosfera, v. 6, n. 11, 2010. 
Von SPERLING, M. Estudos e modelagem da qualidade da água de rios. Belo Horizonte: Ed. UFMG, 2007, 588 p. 